PINTO, P. - O modelo heurístico orgânico na obra de F. W. J. Schelling

\title{
modelo heurístico orgânico na obra de F. W. J. Schelling e sua recepção na Rússia do início do século XIX
}

\author{
[The Organic Heuristic Model in F. W. J. Schelling's Works and its Reception in Russia \\ in the Early $19^{\text {th }}$ Century]
}

http://dx.doi.org/10.11606/1982-88372237377

Pedro Augusto Pinto ${ }^{1}$

\begin{abstract}
Presenting a brief history of the idea of organism throughout the eighteenth century, we will try to describe the developments this idea went through before becoming a fundamental element in the debate on the Russian nationality promoted by Russian literate elite after the Napoleonic Wars. In this process, the ideas developed by German romanticism - in particular those of the philosophers J. G. Herder and especially F. W. Schelling - played a fundamental role. We will thus try to show how some of the thoughts from his so-called "Identity Philosophy", expressed in works such as "Ideas for a Philosophy of Nature" and "Philosophy of Art", were essential for Russian intellectuals and writers to advocate a distinctive artistic and cultural project for their own country.
\end{abstract}

Keywords: Romanticism; Organism; German Philosophy; Nationalism; Russian History

Resumo: Apresentando um breve histórico da ideia de organismo ao longo do século XVIII, tentaremos delinear a trajetória percorrida por ela até o momento em que se tornaria um elemento fundamental no debate sobre a nacionalidade russa promovido pela elite letrada do país após as Guerras Napoleônicas. Nesse trajeto, um papel fundamental é ocupado pelas ideias desenvolvidas pelo Romantismo alemão - em particular as dos filósofos J. G. Herder e, sobretudo, F. W. J. Schelling. Assim, buscaremos mostrar como alguns raciocínios oriundos da sua chamada "Filosofia da Identidade", e expressos em obras como "Ideias para uma Filosofia da Natureza" e "Filosofia da Arte", foram imprescindíveis para que intelectuais e escritores russos pudessem propugnar um projeto artístico e cultural característico para o seu próprio país.

Palavras-chave: Romantismo; Organismo; Filosofia alemã; Nacionalismo; História da Rússia

Zusammenfassung: In einer kurzen Darstellung der Ideengeschichte des Organismus im 18. Jahrhundert werden wir versuchen, die Entwicklungen dieser Idee zu beschreiben, bis sie zu einem grundlegenden Element in der Debatte über die russische Nationalität wurde, welche die gebildete Elite des Landes nach den Napoleonischen Kriegen anstellte. Dabei spielten die Ideen der deutschen Romantik - insbesondere der Philosophen J. G. Herder und F. W. Schelling - eine wesentliche Rolle. Wir werden versuchen zu zeigen, wie einige Gedanken aus Schellings sogenannter "Identitätsphilosophie", wie sie vor allem in den "Ideen für eine Naturphilosophie" und der "Kunstphilosophie" zum Ausdruck kommen, für russische Intellektuelle und Schriftsteller

\footnotetext{
${ }^{1}$ Universidade de São Paulo, Av. Luciano Gualberto, 403, São Paulo, SP, 05508-010, Brasil. E-mail: pedro.augusto.pinto@usp.br. ORCID: 0000-0001-9817-2895
}

(cC) BY-NC

Pandaemonium, São Paulo, v. 22, n. 37, mai.-ago. 2019, p. 377-400 
PINTO, P. - O modelo heurístico orgânico na obra de F. W. J. Schelling

maßgeblich wurden, um ein unverwechselbares künstlerisches und kulturelles Projekt für ihr eigenes Land zu verteidigen.

Stichwörter: Romantik; Organismus; Deutsche Philosophie; Nationalismus; russische Geschichte

\section{Introdução}

O presente artigo pretende abordar alguns reflexos e implicações do princípio heurístico orgânico, conforme a formulação romântica que receberia da filosofia clássica alemã, sobre a literatura e o pensamento russos do início do século XIX - mais especificamente no período compreendido entre a vitória russa sobre as tropas de Napoleão, em 1812, e a Guerra da Crimeia, em 1854, coincidindo aproximadamente com o reinado dos tsares Alexandre I e Nicolau I. Nessa época, sobretudo ao longo das décadas de 1820 e 1830, a então moderna filosofia alemã desfrutou de grande prestígio entre a aristocracia russa letrada, que recebeu com avidez as ideias de Schelling e, sobretudo, de Hegel (BUSHKOVITCH 2014: 183-184; FRANK 2008: 98-99; BILLINGTON 1970: 309-313, 324). O primeiro se insere no rol dos filósofos mais influentes na história intelectual do país eslavo, marcando, com maior ou menor força, figuras tão díspares quanto o anarquista Mikhail Bakúnin e escritor Nikolai Gógol, o radical Vissarion Belínski e o antissocialista Fiódor Dostoiévski. Dentre a sua vasta e diversa produção filosófica, destacaremos as ideias mais ou menos vinculadas à sua Filosofia da Identidade, em suas implicações estéticas e históricas - no que também faremos menção ao pensamento de J. G. Herder, onde se vê com maior clareza a aplicação heurística da ideia de organismo sobre os campos da história e da cultura humanas.

Assim, buscaremos apresentar, apenas panoramicamente, o desenvolvimento da ideia de organismo ao longo do século XVIII e seus desdobramentos sobre o pensamento de Schelling e de Herder, para depois apontar algumas características da recepção, na Rússia à época mencionada, da filosofia alemã em que tal ideia se fez presente. Em seguida, focaremos nossa atenção em alguns desdobramentos específicos da ideia de organismo no pensamento estético e histórico-cultural russo, sobretudo no tocante à polêmica sobre a singularidade histórica do país e sobre sua inserção em uma História Universal. Desse modo, o objeto de análise, aqui, será menos a imensa complexidade das ideias mencionadas, ou dos seus desdobramentos e abordagens nos mais diversos sistemas filosóficos dos séculos XVIII e XIX, do que a trajetória que ele percorreu até se constituir como parte fundamental do debate intelectual de um país que, à época, a 
PINTO, P. - O modelo heurístico orgânico na obra de F. W. J. Schelling

despeito de sua imensa participação no desfecho político das Guerras Napoleônicas, ocupava um espaço marginal no plano do pensamento europeu. Nesse sentido, é importante ressaltar que, feliz ou infelizmente, os palácios intelectuais - para usar uma metáfora de Kierkegaard (apud STEWART 2011: 244) -, erguidos com tanto esmero pelos seus autores, nem sempre são recebidos em toda sua inteireza e majestade quando se arriscam a ir para fora de sua terra de origem, de modo que, ao longo do processo de circulação cultural, à semelhança do que fizeram os otomanos com os monumentos da arquitetura antiga, são às vezes deformados, e têm aceitas no novo edifício cultural apenas aquelas pedras que servem para se erguer uma mesquita. Apontando precisamente para esse fenômeno no caso da recepção das ideias de Schelling na Rússia durante a década de 1820, Koyré (1976: 129) afirma:

De fato, por mais que geralmente se concorde sobre o fato da influência [de Schelling sobre o pensamento russo], e que se reconheça de um modo geral em Gálitch, Vellánski, Davýdov $^{2}$ e Pávlov os intermediários desta influência, obtém-se um fato estranho: toda vez que se procura estudar de uma maneira separada e mais profunda qualquer um desses pensadores, chega-se a este resultado, surpreendente em um primeiro momento, de que, no fundo, nenhum deles jamais foi, propriamente falando, um schellinguiano (tradução nossa).

Estranheza esta que se explica, precisamente, tanto pela influência das vulgarizações filosóficas quanto pelo interesse fatalmente enviesado da intelectualidade russa pelas ideias do grande pensador alemão (KOYRÉ 1976: 198).

\section{Breve histórico da ideia de organismo}

Não obstante suas possíveis relações com a monadologia de Leibniz - cuja referência é direta nas "Ideias para uma filosofia da natureza" de Schelling, e é sugerida na obra de Maupertuis por Ramos (2015: 17-28) - ou mesmo com textos ainda mais antigos da tradição filosófica europeia, a ideia de organismo, entendida como uma ruptura com a concepção mecânica da matéria e com a oposição desta ao espírito, remonta aos debates que dariam origem ao campo da biologia, e que partiram, em larga medida, da impossibilidade dos sistemas cartesiano e newtoniano em explicarem a formação de

2 Para a transliteração dos nomes próprios russos, baseamo-nos na "Tabela de Transliteração do Russo para o Português" do Caderno de Literatura e Cultura Russas, com o adendo já costumeiro de transliterar as vogais fracas russas como vogais fortes sempre que não se encontrem na última sílaba, que estejam em sílaba átona ou que sejam precedidas pelas consoantes líquidas 'l' e 'r'. "Tabela de Transliteração do Russo para o Português", in Cadernos de Literatura e Cultura Russas, no 1, São Paulo, março 2004, p. 393.

Pandaemonium, São Paulo, v. 22, n. 37, mai.-ago. 2019, p. 377-400 
PINTO, P. - O modelo heurístico orgânico na obra de F. W. J. Schelling

corpos organizados na natureza. A compreensão da matéria como algo essencialmente morto, e a consequente abordagem dos seres vivos pela analogia com a ideia de mecanismo (através da qual seu movimento se tornava concebível) não podiam se desvencilhar dos pressupostos, inerentes a tal ideia, de uma intencionalidade e de uma agência externas ao próprio corpo. Lebrun (2002: 330) descreve esta problemática ao comentar o desdobramento específico que ela receberia na filosofia de Kant, onde passaria, na formulação do conceito de 'vivo', pela mesma transformação que buscaremos descrever:

A filosofia kantiana da física opõe um duplo obstáculo à conceptualização do organismo (no sentido moderno da palavra). Em primeiro lugar, o conceito de matéria 'é simplesmente reconduzido a forças motrizes' (Anfangs., IV, 524), de forma que a matéria animada, como qualquer matéria, não pode ser distinguida da matéria bruta. 'Qualquer matéria animada move-se apenas pelo fato de que ela move algo de outro em uma direção oposta e vice-versa.' Compreendamos: apenas enquanto ela obedece à lei da ação e da reação e também à lei da inércia.

Não por acaso, a compreensão mecânica dos seres vivos levaria a formulações que buscavam precisamente a identificação de uma causa externa aos corpos que os mantivesse organizados ou que os tivesse organizado de uma vez por todas, tal como uma hipotética ação constante de Deus para a manutenção da matéria, Sua delegação de tal tarefa a anjos e demônios, uma suposta composição do mundo por matérias plásticas capazes de auto-organização ou o pressuposto da existência do mundo enquanto um desdobramento da criação, em uma temporalidade que para Deus surgiria como simultânea (MAUPERTUIS 1756: 141-142).

Nesse debate, um lugar especial foi ocupado pela formulação do francês PierreLouis de Maupertuis, cujo princípio da mínima ação logrou conciliar os princípios mecânico e finalista em sua explicação do que chamou de corpos organizados, atribuindo à matéria, sem abdicar da lógica causal ou da física newtoniana, finalidades inerentes a ela própria, traduzidas nas ideias de “desejo, aversão e memória”, e que seriam naturalmente buscadas com o mínimo possível de dispêndio de energia. De acordo com o pensador francês, haveria, portanto, certa inteligência na matéria, responsável por fazêla se compor não em massas informes, mas sim em corpos e tecidos específicos, implicando certa proporcionalidade e certa economia na consecução de seus próprios fins. Pela aplicação universal deste princípio, ter-se-ia assim uma tendência inerente à matéria de, sob condições propícias, se organizar em determinados corpos, constatação reforçada 
PINTO, P. - O modelo heurístico orgânico na obra de F. W. J. Schelling

pela observação dos pólipos. Como afirma Lebrun (2002: 347), "que cada parte cortada de um pólipo volte a formar um organismo completo [...] é bem mais do que uma curiosidade, é uma reposição em questão da relação do todo às partes”. Em última instância, tais constatações traziam como implicação que a distinção entre os diversos seres não seria mais qualitativa, entre animados e inanimados, mas sim quantitativa, remetendo-se ao tempo e às condições necessárias para que a matéria se organizasse num determinado corpo ou em outro, com maior ou menor complexidade.

A consequência lógica desse raciocínio, conforme apontado, polemicamente, por Denis Diderot (1953: 69-70), seria uma continuidade na natureza, de modo que seus diversos corpos organizados, tanto orgânicos quanto inorgânicos, se distinguiriam não pela sua essência, mas pela gradação de sua inteligência, compondo, em última análise, um único todo. Somando-se esta gradação ao caráter econômico do princípio da mínima ação, tem-se como resultado que os corpos organizados hão necessariamente de ser mais eficientes do que a razão humana na consecução de seus próprios fins, conforme se vê na maestria inimitável, muito embora surda, de certos animais na produção de seus ninhos, tocas, etc. Como se verá mais adiante, quando transpostas para o campo da cultura e da história humanas, tais decorrências serão fundamentais para o concepção de cultura na filosofia de Herder, assim como para a defesa, na intelectualidade russa, de uma herança cultural e de um desenvolvimento histórico endógenos, opostos à tentativa de transplante da civilização europeia ocidental para as terras do país eslavo.

A formulação de Maupertuis seria levada ainda mais adiante nas reflexões do Conde de Buffon. Nelas, a pressuposição da possibilidade de algo ter sido criado posteriormente à Criação teológica (ou seja, a possibilidade da epigênese) - à qual muitos atribuíam a origem de todos os seres (numa postura preformista) - e o pressuposto da existência não de classes, mas apenas de indivíduos (postura conhecida como nominalismo), permitiram que se passasse a enxergar na natureza tanto uma continuidade nos seus fenômenos quanto uma capacidade de se desdobrar a partir de si mesma, uma vez que não teria sido pré-formada de nenhuma maneira. Tal visão era novamente fortalecida pela existência dos pólipos e também dos zoófitos, a rigor inclassificáveis nos termos das taxonomias tradicionais, de modo que, posta em crise a separação rígida entre os diversos reinos naturais, a concepção contínua dos seres vivos passa a ocupar um lugar privilegiado: 
PINTO, P. - O modelo heurístico orgânico na obra de F. W. J. Schelling

Existe, portanto, nos vegetais e nos animais uma substância viva que lhes é comum, é essa substância viva e orgânica que é a matéria necessária à nutrição; o animal se nutre do animal ou do vegetal, assim como o vegetal pode também se nutrir do animal ou do vegetal decomposto: essa substância nutritiva comum a um e a outro é sempre viva, sempre ativa, ela produz o animal ou o vegetal quando encontra um molde interior, uma matriz conveniente e análoga a um e a outro [...]; mas quando essa substância ativa se encontra reunida em grande abundância nos lugares em que ela pode se juntar, ela forma no corpo do animal outros animais tais quais a tênia, as ascárides, os vermes por vezes encontrados nas veias, nas cavidades do cérebro, no fígado etc. Essas espécies de animais não devem sua existência a outros animais da mesma espécie que eles, sua geração não se faz como a de outros animais; podemos, portanto, crer que são produzidos por essa matéria orgânica, quando ela extravasa ou quando não é bombeada pelos vasos que servem à nutrição do corpo do animal; é bem provável que então essa substância produtiva, que é sempre ativa, e que tende a se organizar, produza os vermes e os pequenos corpos organizados de diferente espécie, dependendo dos diferentes lugares, das diferentes matrizes em que ela se encontra reunida (BUFFON 1836: 474, tradução de Márcio Suzuki)

Tal continuidade, implicada pela onipresença desta "substância viva", se estenderia até mesmo aos seres humanos, que, embora vistos por Buffon como o pináculo da natureza, o seriam apenas por razões quantitativas, vinculadas à diversidade de sua sensibilidade e à possibilidade de se erguerem, pela postura ereta, acima dos outros animais. E é desta assunção da superioridade humana e da unidade gradual entre os seres vivos, implicada pela conjugação de concepções epigenéticas e nominalistas, que se estabelece em Buffon uma hierarquia decorrente do princípio heurístico pelo qual a multiplicidade dos seres se remete a um único "ser prototípico" - justamente o ser humano:

Os animais que mais se assemelham ao homem por sua figura e por sua organização serão portanto, a despeito dos apologistas dos insetos, mantidos nas posição em que estavam, de serem superiores a todos os outros pelas qualidades interiores; e, ainda que sejam infinitamente diferentes das dos homens, que sejam apenas, como provamos, resultados do exercício e da experiência do sentimento, esses animais são, por essas mesmas faculdades, muito superiores aos insetos; e como tudo se faz e que tudo [sic] existe por nuances na Natureza, podemos estabelecer uma escala para julgar os graus das qualidades intrínsecas de cada animal, tomando por primeiro termo a parte material do homem e colocando sucessivamente os animais a diferentes distâncias, conforme efetivamente se aproximem ou se distanciem mais ou menos dele, tanto pela forma exterior como pela organização interna. (BUFFON 1844: 391, tradução de Márcio Suzuki)

Tal hierarquia, por sua vez, se estruturaria em termos simultaneamente morfológicos e econômicos, onde a disposição de uma quantidade limitada de matéria para a constituição de organismos mais ou menos perfeitos implicaria, ao mesmo tempo, a adequação da matéria às funções do organismo - constituindo sua morfologia -, e a articulação dos recursos necessários para este processo - de onde a sua economia -, o que 
PINTO, P. - O modelo heurístico orgânico na obra de F. W. J. Schelling

teria reflexos nos custos reprodutivos e constitutivos de cada corpo e resultaria em perdas onde quer que houvesse um ganho. Entre aspectos morfológicos e econômicos, a organização dos corpos é permeada também pelo conceito de um molde interior, que se remete à própria acepção que se fazia, no século XVIII, da ideia de forma - interna -, oposta à figura - externa -, enquanto explicação da permanência de padrões nos processos reprodutivo e constitutivo.

Utilizando-se da expressão de Maupertuis, desejo, aversão e memória se refletem, assim, na própria organização espacial dos corpos, que segue padrões particulares, distintos dos padrões abstratos da geometria. A centralidade deste molde interior para a constituição de um organismo seria tal que, mesmo no erro, o processo de geração ou crescimento de um corpo nunca poderia ser aleatório, uma vez que o próprio desvio se remete ao que se pressupõe, heuristicamente, como sendo a forma ideal - ainda que esta, cumpre enfatizar, nunca se realize em sua plenitude, mas seja deduzida e realizada, na arte, pela razão humana (Buffon s.d.: 63). Deste modo, o princípio da unidade no ser prototípico acaba trazendo, também, implicações sobre a variedade e a singularidade dos seres na natureza: por derivarem de um único modelo, suas variações se dão, economicamente, a partir do que já se dispunha no ser prototípico, de modo que o crescimento maior de uma determinada parte implica necessariamente a redução de outra. Sendo o ideal - tanto o de cada ser particular quanto o geral - inexistente em sua plenitude, a falha ou a simples alteração em relação a ele já se torna um índice de singularidade. Ademais, a distribuição econômica da massa e do corpo de acordo com a sua especialização se desdobra também em uma correlação psicológica, de modo que cada ser tem a sua característica não apenas física, mas também espiritual.

Inicialmente confinada aos limites das ciências da natureza, tal abordagem estava destinada a transbordar, ao longo do século XVIII, para outras áreas do pensamento. No plano do que, então, passava a ser pensado como o ramo filosófico da Estética, a ideia de perfeição de Buffon seria rapidamente aplicada à conceitualização de beleza: ambas partiriam de uma adequação da matéria ao seu conceito através da sua disposição morfológica e econômica, visando à realização do ideal. Já em Kant, o conceito de uma "natureza prototípica", ou Urwesen, entendido também como harmonização entre causas teleológicas e mecânicas, seria tributário do princípio de Maupertuis e das ideias de Buffon, constituindo um princípio heurístico capaz de associar e comparar fenômenos diversos a partir de uma única raiz comum. De maneira análoga ao desenvolvimento 
PINTO, P. - O modelo heurístico orgânico na obra de F. W. J. Schelling

conceitual que se buscou descrever, Kant também operaria uma transição entre um organismo entendido meramente como composto de partes organizadas - no que não se distinguiria do mecanismo - para um organismo caracterizado como um fim natural, processo no qual a distinção entre a ideia de fim [Zweck] e de intenção [Absicht] seria central (LEBRUN 2002: 344-345).

Ainda assim, a filosofia de Kant representaria uma ruptura significativa com as ideias que se buscou apresentar até aqui. Uma vez estabelecida a exclusividade humana em ser um fim em si mesmo, também o ideal, que em Buffon poderia ser visto como algo presente na natureza, passa a se limitar ao ser humano, que portanto se separa da natureza por uma distinção qualitativa onde o humano surge para o natural como seu fim último e derradeiro e o submete à sua finalidade moral. É precisamente a esta ruptura de ordem qualitativa que se oporão a Filosofia da Identidade de Schelling e o todo o pensamento de Herder, oposição esta que terá consequências significativas sobre as suas formulações acerca da história e da cultura. Tais formulações, por sua vez, correspondem à defesa que se fará, na Rússia, da busca por um desenvolvimento histórico endógeno, distinto do modelo de progresso da Europa ocidental.

\section{Desdobramentos da ideia de organismo nas filosofias de}

\section{Schelling e Herder}

Ao se buscar compreender a presença do modelo orgânico, em sua formulação pela filosofia alemã, na questão nacional russa ao longo da primeira metade do século XIX, é extremamente curioso observar que o nome de Herder - o representante da filosofia alemã de seu tempo que melhor formularia, precisamente a partir dos desdobramentos da abordagem orgânica, as questões acerca da cultura, da diversidade entre os povos e da relação entre esta diversidade e a unidade humana - praticamente não consta em renomadas histórias do pensamento russo como as de Andrzej Walicki (2015), de James Billington (1970), de Alexandre Koyré (1976) e do russo Iuri Mann (1998). ${ }^{3}$ Uma

3 Menção um pouco mais numerosa à presença de Herder no pensamento russo do século XIX pode ser encontrada em Berlin (1994), mas ainda assim esparsa e, como é costume do autor, em meio a tão eruditas quanto genéricas listas de pensadores agrupados de acordo unicamente com a sua própria argumentação, sem adentrar em detalhes no pensamento de cada um e, o que se nos afigura como particularmente delicado, sem apontar quais obras e quais ideias de Herder foram assumidas especificamente por quais pensadores russos e em que contextos particulares de sua produção. Herder é também compreendido por Berlin à luz de uma conceitualização criticável de Romantismo, entendido

Pandaemonium, São Paulo, v. 22, n. 37, mai.-ago. 2019, p. 377-400 
PINTO, P. - O modelo heurístico orgânico na obra de F. W. J. Schelling

referência ligeiramente mais detalhada pode ser encontrada na obra de Gulyga (1975), onde se menciona sem maiores detalhes uma grande receptividade à obra de Herder na Rússia, que se teria refletido nas obras de Aleksandr Radíchtchev (1975: 168), ${ }^{4}$ e na compra pela universidade de Tártu (então parte do Império Russo), em 1805, da biblioteca do renomado pregador de Riga em um leilão que se seguiu à sua morte (1975: 174) - com a curiosidade um tanto trágica de que metade dos livros se perderia em um naufrágio.

Tal lacuna historiográfica é confirmada por Júkova (2007), única obra de fôlego atualmente disponível a esse respeito. ${ }^{5}$ De acordo com a pesquisadora russa, o tema da recepção da obra de Herder na Rússia foi abordado pela primeira vez, ainda que em termos puramente panorâmicos (o trabalho abrangia também a República Tcheca e a Polônia), em um artigo do pesquisador alemão Konrad Bittner (JúKOvA 2007: 8), que posteriormente teria se detido com maior vagar sobre as influências do filósofo sobre o escritor e historiador Nikolai Karamzin, sobre o já mencionado Radíchtchev e sobre o poeta Gavrila Derjávin. Segundo Júkova, Bittner teria sido o primeiro, senão o único, a ter estudado a influência de Herder sobre os pensadores russos de maneira minimamente aprofundada. Na própria Rússia, o primeiro panorama acerca da questão surgiu apenas em um artigo de 1980, dedicado especificamente à influência de Herder sobre os estudos de literatura comparada (IDEM: 9). Embora se reconhecesse amplamente, por exemplo, a influência de Herder sobre a obra de Radíchtchev, até a edição do livro de Júkova nenhum trabalho especificamente sobre esta influência jamais havia sido escrito (IDEM: 29). Ainda assim, a autora afirma que o interesse pela obra de Herder, tanto poética quanto filosófica,

como um anti-iluminismo (BERLIN 2002, 2015), que mais dificulta do que colabora na tarefa de compreender o autor e sua recepção de um ponto de vista histórico, como tentamos, por exemplo, fazer aqui, ao remeter as ideias de dois românticos como Herder e Schelling a um iluminista por excelência como Buffon. Ademais, Berlin tem o costume de não dar voz aos autores que menciona, raramente recorrendo à citação direta ou indicando de maneira precisa as suas fontes, o que impossibilita a leitura crítica e comparativa de suas análises conjuntamente com as outras que apresentamos aqui.

4 Autor de "Viagem de São Petersburgo a Moscou" (1790), obra cuja publicação lhe renderia, pela descrição das condições econômicas e sociais - e sobretudo da servidão - na Rússia de Catarina II, um exílio na Sibéria.

5 A obra de Júkova se destaca pela abrangência de seus estudos (que abordam a influência de Herder na Rússia desde finais do século XVIII até o início do século XX), e pela indicação de uma lacuna historiográfica que vem, aos poucos, sendo preenchida. Ainda assim, excetuando-se algumas menções a bibliotecas particulares, arquivos e reminiscências, a autora nem sempre fornece suficiente evidência documental para a sua análise, valendo-se não raro apenas de comparações entre as ideias de pensadores russos e as propagadas pelo filósofo alemão sem demonstrar uma relação direta de causalidade entre elas. No tocante a presença do pensamento de Herder especificamente no debate sobre a nacionalidade russa, Júkova menciona que a ideia de uma arte e de uma cultura autenticamente nacionais foi advogada sob a influência do filósofo na década de 1800 pela Sociedade Literária Amistosa [Drújeskoie Literatúrnoie Óbchtchestvo], mas não indica se os projetos e ideias do grupo tiveram continuidade ao longo das décadas seguintes, quando o debate finalmente assumiria, sob feições assumidamente românticas, o primeiro plano das discussões literárias (2007: 79-80).

Pandaemonium, São Paulo, v. 22, n. 37, mai.-ago. 2019, p. 377-400 
PINTO, P. - O modelo heurístico orgânico na obra de F. W. J. Schelling

teria surgido na Rússia ainda durante a vida do autor, marcando, para além do já citado Radíchtchev, sobretudo a obra de Karamzin, que publicou trechos traduzidos da obra do filósofo e fez questão de conhecê-lo pessoalmente em suas viagens pela Alemanha na década de 1790 (2007: 4, 51). O teor dos relatos do historiador leva a autora a crer que Herder já fosse razoavelmente conhecido entre o público letrado russo da época, mas não são trazidas maiores evidências nesse sentido.

Se a falta de pesquisas sobre a recepção de Herder na Rússia resulta de uma relativa irrelevância do autor na paisagem intelectual do país no início do século XIX ao menos quando comparada com a de outros autores alemães -, não compete, feliz ou infelizmente, a este artigo resolver. O que interessa notar, no que nos tange, é como alguns pensadores russos de peso no cenário crítico e literário da época chegaram a expressar ideias extremamente semelhantes às do autor de "Também uma filosofia da história para a formação da humanidade", sem, todavia, mencionar o seu nome uma única vez. Já ao nome de Schelling, pelo contrário, encontram-se menções numerosas, tanto nos textos de época quanto na historiografia, sendo a partir de suas ideias sobre a mitologia que um eslavófilo ${ }^{6}$ influente, Ivan Kiréevski, tirará suas reflexões acerca da divisão original dos povos e do valor filosófico de suas crenças específicas. Neste sentido, buscaremos explicitar brevemente as ideias dos dois filósofos alemães que mais ressonância teriam na vida intelectual russa da primeira metade do século XIX, seja pelo contato e pela influência direta que exerceram sobre o país eslavo - no caso de Schelling -, seja pela intrigante coincidência de suas concepções históricas com as de determinados pensadores russos - no caso de Herder.

Sem risco de exagero, pode-se dizer que poucos pensadores europeus, ou estrangeiros de modo geral, exerceram tanta influência sobre a cultura russa no século XIX como Schelling, ainda que isso não implicasse uma compreensão precisa de suas ideias. O escritor Vladimir Odóevski o comparava a Colombo; de maneira análoga, em carta direta ao pensador alemão, o polemista Piotr Tchaadáiev lhe confessaria que sua filosofia lhe havia aberto "novos mundos" (apud PustarnákOv 2001: 82, 189). Assim como eles, uma enorme lista de personalidades russas influentes nos debates político, filosófico e literário do século XIX dedicaria ao menos uma linha de suas obras à

6 Eslavófilos eram os partidários de um projeto nacional autóctone para a Rússia nas décadas de 1840 e 1850, e se opunham aos ocidentalistas, que defendiam a modernização do país sob o modelo da Europa ocidental. 
PINTO, P. - O modelo heurístico orgânico na obra de F. W. J. Schelling

importância que o filósofo de Vurtemberga teria tido sobre a sua formação. ${ }^{7}$ Dentre a vastidão de seu pensamento, e dentre as distintas fases que este atravessaria no decorrer da longa vida do filósofo, de particular relevância foram as suas ideias acerca da natureza, da relação de identidade entre esta e o espírito e da consequente importância da mitologia e da arte simbólica enquanto expressões do absoluto. Com efeito, ao se referir a um dos principais divulgadores da obra de Schelling na Rússia, Koyré (1976: 138) observa com certo espanto que mesmo tendo acesso à produção posterior do filósofo - resultado dos inúmeros desdobramentos e renovações intelectuais pelas quais passaria Schelling em sua longa vida -, pode-se notar entre a intelectualidade russa uma permanência duradoura especificamente das ideias expressas em sua filosofia da natureza e em seu sistema da identidade, razão pela qual nos focaremos particularmente nesta parte de sua obra.

Em seu livro "Ideias para uma filosofia da natureza", Schelling parte da investigação acerca da possibilidade e da necessidade da representação, por parte do espírito, dos processos e seres a eles externos - no que se inclui, acima de tudo, a natureza -, para chegar no problema da relação entre sujeito e objeto, debatendo, sem nomeá-la, a filosofia crítica de Kant. Contrapondo-se à possibilidade de formas apriorísticas carentes de conteúdo, e de, vice-versa, conteúdos despidos de qualquer forma, Schelling retoma os sistemas de Espinoza e de Leibniz para tentar estabelecer uma relação necessária entre o mundo dos fenômenos e as representações que dele são feitas no âmbito do espírito. Rejeitando, por vê-la como uma anulação da liberdade na esfera do todo, a ideia espinozana de uma substância primordial na qual espírito e matéria estariam originalmente interligados, Schelling retoma a monadologia de Leibniz para, simultaneamente, afirmar a necessidade de uma correspondência entre os fenômenos externos e as representações internas às próprias mônadas (contrapondo-se, assim, à ideia de que os fenômenos agiriam sobre o que é concebido essencialmente como um sistema fechado e puramente ativo), e também para esmiuçar a ideia de uma harmonia universal preconcebida que garantiria, supostamente, a correspondência já mencionada. Recusando-se a ver aí qualquer espécie de agência divina, pelo fato de semelhante relação não poder ser considerada necessária, Schelling é finalmente levado a concluir pela presença de algo familiar ao espírito nos fenômenos fora dele - ou seja, pela presença do próprio espírito em todos os fenômenos naturais (SCHELLING 2001: 99-100). Como

7 Nesse sentido, chama a atenção o volume de textos inseridos na coletânea "Schelling: pro et contra" todos relacionados de alguma forma à filosofia de Schelling -, assim como a própria iniciativa de se organizar um livro com documentos acerca da recepção do filósofo pela intelectualidade russa.

Pandaemonium, São Paulo, v. 22, n. 37, mai.-ago. 2019, p. 377-400 
PINTO, P. - O modelo heurístico orgânico na obra de F. W. J. Schelling

argumento, apresenta a relação intrincada entre ideia e matéria que se pode observar em qualquer organismo, que tende a se organizar conforme o conceito de si mesmo, e deduz a partir daí tanto a necessidade da relação entre os fenômenos e o espírito quanto a identidade entre espírito e matéria - de onde se origina uma relação de continuidade entre o humano e o natural que se refletirá fatalmente na sua concepção da mitologia. Aqui já se pode ver com clareza a faceta metafísica que a discussão iniciada por Maupertuis tomaria no final do século XVIII.

A partir do momento em que a identidade entre o ideal e o real é colocada, e em que o absoluto é tido como a total indiferença entre estas suas duas potências, a mitologia e arte assumem para a filosofia de Schelling um papel fundamental (SCHELLING 2010: 44). Por garantirem a presença do universal em formas singulares, a mitologia e a arte, em sua vertente simbólica, se constituem na expressão por excelência do absoluto, uma vez que representam a manifestação sensível de ideias - não na forma de alegorias, mas sim de tautogorias. Aqui, cumpre observar que, ainda que o foco mitológico de Schelling costume recair sobre o universo greco-romano, o papel que ele lhe atribui, quando articulado à presença do espírito na natureza e à continuidade entre esta e a humanidade, traz consequências importantes sobre a forma de se pensar a mitologia dos diversos povos de um modo geral. De superstição nefasta, ou de reles alegoria para uma verdade exterior, ela passa a ser vista como a expressão primordial de uma experiência humana ainda integrada à natureza, na forma de uma produção inconsciente, orgânica, de seres mitológicos e ideais enquanto forças e processos naturais. De um ponto de vista histórico, tal processo teria sido interrompido pela atividade reflexionante do espírito, que levou à produção de ideias puras e abstratas, mas que deveria, numa perspectiva programática, traçar o caminho de volta (SCHELLING 2001: 38), visando à elaboração de uma nova mitologia derivada da liberdade.

E é nesse ponto que o pensamento de Schelling se cruza com o de Herder. Mais especificamente preocupado com questões históricas e, pode-se dizer, antropológicas, Herder configuraria, já em uma de suas primeiras obras, "Também uma filosofia da história para a formação da humanidade", um deslocamento importante em relação à concepção iluminista de progresso - o título da obra, em si, já seria uma resposta ao livro de Voltaire (HERDER 2000: 9) -, e mostraria de maneira clara as consequências da aplicação da abordagem que se buscou descrever até aqui sobre o campo da história e da cultura humanas. A primeira delas, a partir da qual se estruturará toda a concepção 
PINTO, P. - O modelo heurístico orgânico na obra de F. W. J. Schelling

herderiana da humanidade, é o princípio da continuidade entre os seres humanos e a natureza, em oposição à ruptura defendida por Kant em virtude da moralidade. Tal continuidade implica, em primeiro lugar, uma relação de contiguidade entre a História Natural e a História humana, e por conseguinte permite que o mesmo princípio que se utilizou para analisar os fenômenos da natureza seja aplicado também na análise dos fenômenos antrópicos. A razão humana seria, assim, apenas a culminância de graus de sensibilidade já presentes na natureza; os primeiros homens teriam sido "pequenos deuses audaciosos", que ocuparam as terras inabitáveis e criaram a linguagem, de modo que a cultura seria ela mesma um monumento da História Natural.

Deste modo, as mesmas características que haviam sido observadas na natureza no pensamento de Buffon passam a ser aplicadas ao campo da cultura humana, entendida na sua variedade espacial e temporal. Da mesma forma que a natureza se desdobra em uma multiplicidade de seres, cada um de acordo com o seu próprio ideal, todas as mais diversas variações e especificidades culturais serão vistas por Herder como manifestações possíveis das mesmas potencialidades humanas, todas igualmente ricas e expressivas da sua capacidade ideal. A possibilidade de seu maior ou menor desenvolvimento não se dá por mérito ou por distinções essenciais, mas sim pela conjugação de fatores externos com as índoles individuais de cada povo e cada época. Por outro lado, de acordo com o mesmo princípio que havia sido exposto em relação à composição dos animais, também as potencialidades humanas efetivas implicarão sempre o abandono de alguma outra potencialidade - sendo esta mais uma razão para a sua diversidade. Não por acaso, Herder lança mão da metáfora da pintura, onde as diversas culturas humanas são vistas como tons ou gradações de um único quadro: a Humanidade. Em consonância com o que se havia estipulado acerca dos fins inerentes à matéria, Herder também passa a enxergar fins inerentes a cada povo e a cada cultura, desdobrando a ideia iluminista de progresso, unilinear, em uma tendência geral à perfectibilidade, matizada de acordo com as condições específicas de cada povo. Afastando-se do que considera uma arrogância de seu século diante das outras épocas e das outras nações do mundo, Herder afirma, assim, que cada povo, em cada época, tende à consecução de seus próprios fins, que se inscrevem de modo particular na totalidade das inclinações humanas - de modo análogo ao que Schelling afirmaria sobre os organismos em suas "Ideias", e ao que Maupertuis e Buffon haviam elaborado em suas considerações sobre a natureza (HERDER 2010: 182). 


\section{A recepção da filosofia alemã e a questão nacional na Rússia}

É curioso observar como o mesmo caminho percorrido pelo modelo heurístico orgânico na filosofia ocidental ao longo do século XVIII seria traçado, em pouco mais de 20 anos, no que à época constituía o ainda incipiente pensamento russo. Sendo recepcionadas sobretudo pelo campo da filosofia acadêmica e da filosofia da natureza, as ideias de Schelling seriam rapidamente desdobradas para o plano do pensamento histórico - o que é ainda mais notável se observarmos, mais uma vez, a aparente ausência na historiografia de menções à presença de Herder no pensamento russo. ${ }^{8}$ Ainda assim, o simples desdobramento mitológico da filosofia de Schelling já poderia, por si só, trazer consequências importantes para a forma como um país que pensava a si mesmo como assolado pela superstição passaria a enxergar a sua própria história.

À semelhança dos territórios que compunham a moderna Alemanha, a questão da unilinearidade histórica proposta pelo iluminismo francês não poderia deixar de repercutir na sociedade russa, fadada a enfrentar a questão da ocidentalização desde finais do século XVII e sobretudo no início do século XVIII - quando a construção da nova capital, São Petersburgo, encarnaria por excelência o processo de modernização. Sem adentrar em meandros pormenorizados do contexto cultural alemão que gestaria a sua filosofia no século XVIII, é importante mencionar algumas distinções fundamentais que teriam grandes implicações sobre a recepção da fillosofia alemã pela intelectualidade russa. Tal importância deriva do fato de, a despeito de se constatar uma ávida importação das principais correntes do pensamento europeu do período, não se poder encontrar na Rússia um debate filosófico com a mesma profundidade ou tampouco a mesma sistematicidade que se podia observar na França ou na Alemanha da mesma época. Tal distinção, longe de se dever a qualquer "inferioridade nacional", como sempre aventado por uma parte da própria opinião pública dos países ditos atrasados, se deve a certas condições objetivas

8 A chave para essa conjunção entre ausência e coincidência é sugerida por Júkova (2007: pp 87-93). Se na virada do século XVIII para o XIX, num ambiente ainda profundamente marcado pelo Iluminismo, a obra de Herder era apreendida como a obra de um filósofo e de um historiador, nas décadas de 1820 e 1830 Herder era visto na Rússia sobretudo como um poeta. Tal fato pode explicar a sua ausência nos estudos sobre o nacionalismo nas décadas de 1830 e 1840 aos quais nos remetemos. Mesmo que o interesse por suas interpretações históricas fosse mantido pela revista "O Mensageiro Moscovita" [Moskóvskii Viéstnik] e sobretudo por seu editor, Mikhail Pogódin, o esforço deste em divulgar a obra de Herder testemunhava certo esquecimento e pouca familiaridade com a obra propriamente histórica e filosófica do alemão - ainda que seu nome fosse conhecido, conforme atestam os versos do $8^{\circ}$ capítulo do Evguêni Oniéguin, de Aleksandr Púchkin, onde Herder é listado junto com inúmeras outras leituras ao gosto da moda da época.

Pandaemonium, São Paulo, v. 22, n. 37, mai.-ago. 2019, p. 377-400 
PINTO, P. - O modelo heurístico orgânico na obra de F. W. J. Schelling

de reprodução dos bens culturais, assim como ao efeito que tal fluxo de ideias teria sobre determinadas camadas da sociedade.

É lícito apontar - de maneira simplificada, mas nem por isso errônea - uma série de fatores na circulação de bens culturais no território de língua alemã que desempenharam um papel propício ao desenvolvimento de sua filosofia do modo abstrato, sistemático e de pretensões universais com que se deu (HOBSBAWM 2010: 391-395). A presença do protestantismo, com suas inegáveis implicações no processo de disseminação da leitura, e a presença socialmente considerável de uma classe média - composta por funcionários públicos, clérigos e profissionais liberais - garantiriam, ao longo do século XVIII, uma expansão nada desprezível do público leitor e dos hábitos de leitura da população. A relativa proximidade da França, que se tornara, no século XVIII, a Meca do pensamento e da ideologia do progresso, facilitava a recepção e a incorporação do pensamento francês produzido no seu tempo, do mesmo modo que uma sólida tradição editorial, universitária e filosófica garantia que a leitura da filosofia francesa e inglesa não havia de se dar de modo passivo ou mimético, mas sim reflexivo. A fragmentação territorial favorecia a liberdade de imprensa, uma vez que textos proibidos em determinado Estado poderiam ser facilmente publicados no Estado vizinho. Ao mesmo tempo, é lícito supor que a ausência de condições objetivas de desenvolvimento análogas às que na época já se tornavam o eixo da moderna civilização burguesa - a centralização estatal e o desenvolvimento das forças produtivas - favorecia a formulação de ideias de caráter majoritariamente abrangentes, sem se ater a fenômenos específicos a não ser como ferramenta para a elaboração de teses gerais (BARKER 2004: 69-86).

Bem distintas eram as condições intelectuais do império russo na primeira metade do século XIX, ainda que, em larga medida, se pudesse dizer que partilhasse com a Alemanha a condição de Estado periférico ao eixo da Dupla Revolução. Levada a assimilar, a toque de caixa, aspectos seletivos da civilização ocidental ao longo do século XVIII, sua entrada no século XIX seria marcada pelo advento dos refluxos que se fariam, a partir de então, tão presentes em seu processo de modernização intelectual e sociopolítica. Com a eclosão da Revolução Francesa, ainda sob o cetro de Catarina II, a relativa liberdade de imprensa e de expressão garantida à nobreza esclarecida ao longo de seu reinado seria radicalmente revertida. O sucessor de Catarina, Paulo I, tratou de aprofundar ainda mais a reação, e, não obstante o breve período de liberdade que se seguiria nos primeiros anos do reinado de Alexandre I, a guerra com a França 
PINTO, P. - O modelo heurístico orgânico na obra de F. W. J. Schelling

napoleônica, a progressiva imersão do tsar no misticismo reacionário, e o próprio papel geopolítico desempenhado pela Rússia no Congresso de Viena e na Santa Aliança gerariam um ambiente intelectual cada vez mais marcado pela censura e pela repressão num processo que seria coroado pela reação do governo ao pronunciamento militar de dezembro de $1825 . .^{9}$ A este quadro político se somavam um público leitor estreito, concentrado nas duas capitais, e a ausência de uma tradição sólida de pensamento filosófico (BARKER 2004: 224-241).

Dado ainda o banimento das questões propriamente políticas do debate público, favorecendo a disseminação de questões, ao menos na aparência, puramente filosóficas ou literárias, tem-se o contexto em que se deu a recepção de boa parte da filosofia alemã então contemporânea, com a obra de Schelling se destacando como uma das mais prestigiadas. Koyré (1976: 43) sugere dois fatores fundamentais que teriam gerado na intelectualidade russa uma grande receptividade à então moderna filosofia alemã: de um lado, uma crescente galofobia, surgida em finais do século XVIII e exacerbada com a invasão de Napoleão, e de outro uma presença cada vez maior de Gelehrte alemães nos meios universitários russos, que haviam conhecido um breve período de expansão nos anos iniciais de Alexandre I. Pustarnákov (2001: 3), por sua vez, divide a recepção da obra de Schelling em três meios distintos da circulação de bens culturais na Rússia da época: o acadêmico, o religioso e o independente. Considerando que os dois primeiros teriam de suportar, a partir da guinada reacionária de Alexandre I, o jugo pesado da censura religiosa, que considerava a filosofia de Schelling um panfleto panteísta e, portanto, oposta à doutrina da revelação, foi apenas no terceiro ambiente que as ideias de Schelling puderam ser apreciadas com maior abrangência. Ainda que isso implicasse uma fatal falta de rigor, o prestígio desfrutado pela metafísica alemã nesse meio era imenso, conforme observou em suas memórias o príncipe Vladimir Odóevski (apud KOYRÉ 1976: 49), dizendo que “[...] a metafísica formava o fundo de nossa atmosfera espiritual [...]. Nós acreditávamos na possibilidade de uma teoria geral, com a ajuda da qual seria possível reconstruir todos os fenômenos da natureza $[\ldots]$ ]". Tal prestígio, e sobretudo o desfrutado por Schelling, pode ser observado não apenas no entusiasmo de seus

9 O Pronunciamento Dezembrista, assim chamado por ter ocorrido em 14 de dezembro de 1824, foi uma revolta de setores progressistas do oficialato russo rebelada no dia da coroação do futuro tsar Nicolau I. A pauta da revolta era vaga, e ia da exigência de um governo constitucional à coroação do arquiduque Constantino e à abolição da servidão. Sem qualquer apoio amplo da sociedade, o motim foi rapidamente desbaratado, e foi o marco de uma era de profunda repressão e reacionarismo políticos, sendo os envolvidos mandados para o Cáucaso e para a Sibéria. 
PINTO, P. - O modelo heurístico orgânico na obra de F. W. J. Schelling

defensores, mas sobretudo no ódio de seus detratores, dentre os quais a ponta de lança se encontrava dentro do próprio Estado, conforme se lê no relatório de Mikhail Magnítski, responsável pela reforma universitária de Alexandre I, em 1819:

Não é apenas a filosofia francesa, a dos Voltaire, dos Bayle, nem são apenas as doutrinas de Kant que trazem consigo a marca visível de sua inspiração diabólica. A filosofia alemã, especialmente a de Schelling, é talvez ainda mais perigosa, sendo, como é, mais bem camuflada. Ora, a essência e a base desta filosofia não são nada mais nada menos do que o livre-pensamento e a depravação (apud KOYRÉ 1976: 95, tradução nossa).

Voltando, porém, a Odóevski, seu testemunho nos é de particular relevância, na medida em que foi um dos mais influentes participantes da sociedade secreta autodenominada "Sociedade da Filosofia" [Óbschestvo Liubomúdriia], ${ }^{10}$ de grande importância em meio ao contexto da recepção leiga da filosofia alemã na Rússia, e cujos membros, inicialmente interessados na estética e na filosofia da natureza de Schelling, passariam a conjugar ambas com a preocupação com a questão nacional. ${ }^{11}$ Esta passava a se impor à intelectualidade russa com cada vez mais força em virtude de uma série de fatores históricos que se acumularam ao longo do século XVIII e que despontaram de maneira particularmente aguda no início do século XIX.

Em linhas gerais, para além do confronto de pelo menos um século com o paradigma civilizacional da Europa ocidental, imposto a partir do momento em que a coroa russa enxergou nesta um modelo administrativo, cultural e econômico a ser perseguido, e para além dos fenômenos históricos de ordem pan-europeia (secularização, esforço administrativo de uniformização social, aumento do fluxo comercial, crise do exército mercenário ante as tropas revolucionárias francesas), a intelectualidade russa que começava a se interessar pelas obras dos filósofos alemães havia passado pela experiência, inédita até então, de se ver triunfar militarmente sobre o homem que pusera

10 A palavra liubomudriie é um decalque russo para a palavra filosofia, onde liubo=filo e mudriie $=$ sofia. O termo que vingou, todavia, seria o de origem grega, filosófiia. Ainda assim Koyré (1976: 186) observa que boa parte do vocabulário filosófico que surgia então pela primeira vez em língua russa foi composto precisamente por decalques vindos dos termos da filosofia alemã, como por exemplo vseedínstvo (Alleinheit), tsiélostnost' (Ganzheit), samosviédenie (Selbstwissen), mirovozriéniie (Weltanschauung), narodnost' (Volkstum) etc.

11 No tocante à recepção de Herder pelos membros da Sociedade da Filosofia, Júkova aponta que a sua filosofia da história era vista por eles como apenas "uma variação literária da Filosofia da Identidade de Schelling” (2007: 93). De acordo com a autora, Odóevski via em Herder antes de tudo um poeta, no que não se distinguia da interpretação dominante no seu tempo. As ideias do pregador de Riga teriam sido assim assimiladas na década de 1830 conjuntamente com as de Schelling e sem grandes distinções, ambas colaborando para compor o fenômeno intelectual chamado de "schellinguianismo russo" [rússkoie schellingiánstvo] da década de 1830. Pelo próprio nome já se vê a qual dos dois pensadores caberia o maior prestígio.

Pandaemonium, São Paulo, v. 22, n. 37, mai.-ago. 2019, p. 377-400 
PINTO, P. - O modelo heurístico orgânico na obra de F. W. J. Schelling

todo o continente europeu de joelhos. Ademais, para os muitos letrados que compunham o oficialato do exército, a vitória contra Napoleão também implicou pela primeira vez um contato direto com a Europa ocidental, onde puderam sentir pessoalmente o contraste cultural entre esta e a Rússia, e onde tiveram um longo convívio com as tropas de seu próprio país, oriundas de realidades sociais bastante distintas das da nobreza à qual pertenciam.

A filosofia do romantismo alemão seria recebida na Rússia, assim, em um contexto onde a discussão sobre os rumos do país e sobre o papel específico do povo russo na história da humanidade estava na ordem do dia, o que teve como consequência o fato de as ideias e temáticas abordadas originalmente no âmbito da filosofia da natureza serem progressivamente transpostas para as questões históricas e culturais. É o que vemos em um texto programático da "Sociedade da Filosofia" escrito por um de seus membros filosoficamente mais brilhantes, Dmitri Venevitínov (apud KOYRÉ 1976: 217-220): tal como a matéria, à semelhança do ser humano, agiria livremente em sua simultânea espiritualidade, e de acordo com seus fins particulares, para se autorrealizar, também os povos agiriam no sentido de expressar e realizar a sua essência particular a partir de seus próprios fins, cumprindo apenas, para que isso ocorra, que tomassem consciência de sua especificidade humana. No caso concreto da Rússia, Venevitínov constatava que a opção pelo paradigma civilizacional que imperara ao longo de todo o século XVIII - a Europa ocidental - teria levado a Rússia a uma civilização postiça, exterior, e que, enquanto se insistisse na sua manutenção, o povo russo jamais seria capaz de se expressar ou de realizar a sua missão histórica particular. Tal processo de autoconhecimento implicaria, simultaneamente, aprofundar-se em si mesma e elaborar uma expressão civilizacional própria e singular, ou seja, uma arte e uma cultura indubitavelmente russas, que levassem o povo russo ao autoconhecimento. E foi seguindo um raciocínio análogo ao de Venevitínov que outro proeminente membro da Sociedade da Filosofia, Ivan Kiréevski, saudou a obra de Aleksandr Púchkin como sendo, finalmente, a expressão nacional que tanto se aguardava (KOYRÉ 1976: 237-238). Aqui, a importância atribuída à arte no processo de aquisição da consciência de si por parte de um povo nos remete não apenas às ideias de Schelling sobre a mitologia, mas, novamente, às ideias de Buffon (s.d.: 63), para quem apenas a arte era capaz de deduzir, da multiplicidade e das irregularidades existentes entre os indivíduos de uma mesma espécie, o seu protótipo ideal:

não foi pela comparação do corpo de um homem com o de outro homem, ou pelas medidas tomadas atualmente de um grande número de sujeitos, $[\ldots]$ foi pelos esforços

Pandaemonium, São Paulo, v. 22, n. 37, mai.-ago. 2019, p. 377-400 
PINTO, P. - O modelo heurístico orgânico na obra de F. W. J. Schelling

que se fizeram para imitar e copiar exatamente a Natureza, é à arte do desenho [dessein] que se sabe tudo o que se saber nesse gênero, o sentimento e o gosto fizeram aquilo que a arte mecânica não podia fazer; deixou-se de lado a régua e o compasso para se ater ao golpe de vista, realizaram-se no mármore todas as formas, todos os contornos de todas as partes do corpo humano, e se conheceu melhor a Natureza pela representação do que pela própria Natureza; desde que houve estátuas, julgou-se melhor a perfeição delas ao vê-las do que ao medi-las. Foi graças a um grande exercício da arte do desenho e a um gosto delicado que os grandes escultores chegaram a fazer sentir aos outros homens as justas proporções das obras da Natureza; os antigos fizeram estátuas tão belas, que, de comum acordo, foram vistas como a representação exata do corpo humano mais perfeito (tradução de Márcio Suzuki).

É nesse sentido que Koyré (1976: 14) enfatiza o papel crucial exercido pela filosofia do romantismo alemão para a concepção orgânica de história que seria formulada pela "Sociedade da Filosofia", quando esta passou a se preocupar com o sentido de sua própria nacionalidade. Não por acaso, Ivan Kiréevski também se destacaria posteriormente como mentor intelectual do grupo eslavófilo, onde o modelo orgânico das "Ideias para uma filosofia da natureza" e a defesa de uma singularidade histórica russa estariam novamente articulados. Em seu artigo "O discurso de Schelling” (Rietch' Schellinga), de 1845, comentando um discurso do filósofo alemão a respeito do deus Jano, Kiréevski parte do papel que Schelling atribui à mitologia para estabelecer a relação entre esta e a constituição de uma comunidade enquanto povo:

Os mitos não podem ser inventados; pois, caso contrário, surge a pergunta: quem os inventou? Alguém sozinho não os poderia inventar, pois a mitologia cresce com o povo de um tal jeito, que considerá-la como algo inventado é a mesma coisa que deduzir a língua de um povo de uma obra de uma pessoa qualquer. E como é que o inventor poderia transmitir suas ideias para um povo, e obrigá-lo a acreditar que as suas invenções são deuses reais? É até mais fácil supor que a mitologia é a invenção de um povo inteiro; mas seria difícil explicar semelhante condição poética historicamente. Aliás, tal suposição seria a mais razoável de todas, se não encontrasse oposição na própria ideia de povo. Pois o que é um povo e o que faz uma reunião de pessoas um povo? Não é a vida conjunta de muitas pessoas separadas que compõe um povo, mas a coletividade $\left[o ́ b c h t c h n o s t^{\prime}\right]^{12}$ de consciência, que se expressa exteriormente na língua, e interiormente na partilha [óbchtchnost'] de um único olhar para a ordem das coisas e do mundo, uma unanimidade da qual se originam a moral e os costumes. Essa coletividade [óbchtchnost' ] de visão acerca da ordem e da constituição original das coisas não é nada mais, nada menos, do que a religião, que nos povos antigos se manifesta na forma da mitologia (apud PUSTARNÁKOV 2001: 224-225, tradução e grifo nosso).

Não obstante a longa exposição que o artigo propõe acerca da religião no sistema de Schelling, surge com clareza a relação, orgânica, entre um determinado grupo de

12 O termo deriva do adjetivo óbchtchii, 'comum', 'coletivo', que dá origem às palavras óbchtchestvo, sociedade, e obchtchina, comuna camponesa.

Pandaemonium, São Paulo, v. 22, n. 37, mai.-ago. 2019, p. 377-400 
PINTO, P. - O modelo heurístico orgânico na obra de F. W. J. Schelling

pessoas e um determinado sistema mitológico, numa relação análoga à proposta por Schelling, em suas "Ideias", para a compreensão dos seres vivos enquanto um todo inseparável entre ideia e matéria. Cumpre destacar que, no debate acerca da nacionalidade russa, a religião, por razões tanto históricas quanto ideológicas - e cumpre mencionar a existência de certa tradição, bem estabelecida, que considerava Moscou a "Terceira Roma” após a queda de Constantinopla (apud ETKIND et al.1992: 185-193) -, ocupava um papel fundamental: ao contrário da igreja católica ou das igrejas reformadas, a igreja ortodoxa russa se identificava especificamente com o Estado e o território do país, e mais de uma vez se atribuiu, com conotações positivas ou negativas, a diferenciação entre a Rússia e a Europa ocidental à ruptura entre a ortodoxia e as vertentes ocidentais do cristianismo. Segundo Tchaadáiev - ávido leitor de Schelling, mas influenciado sobretudo pelo catolicismo reacionário de Joseph de Maistre -, o isolamento da igreja russa teria sido a razão da sua desgraça (apud GOMIDE 2013: 77-78), ao mesmo tempo em que, ao longo do século XIX, a identidade entre o povo russo e a sua vertente específica do cristianismo seria o objeto de diversos discursos nacionalistas de cunho messiânico, entre os quais merecem destaque as concepções de Fiódor Dostoiévski. Segundo o escritor, seria precisamente a sua forma supostamente primitiva de cristianismo que caracterizaria a potencialidade do povo russo, e o que lhe garantiria, portanto, um papel singular na história universal (FRANK 2008: 329). Guardadas as devidas diferenças, tem-se aqui um desdobramento das potencialidades que Herder atribuía aos diversos povos, transferidas para um debate histórico e religioso e, em certa medida, instrumentalizadas para fins ideológicos.

É interessante observar como, já na "Sociedade da Filosofia", se manifesta a oposição simbólica entre as então duas capitais do império russo, Moscou e São Petersburgo, uma vez que os seus membros marcariam presença como um grupo intelectual essencialmente moscovita. Para tanto, muito contribuiu o fato de que ainda era possível frequentar cursos sobre a doutrina de Schelling na Universidade de Moscou, mascarados de cursos de agronomia, mesmo depois de a repressão acometer outras grandes universidades do país (KOYRÉ 1976: 157). Já no plano simbólico, enquanto a cidade construída por Pedro, o Grande, era o símbolo russo de um projeto europeu, imposto pela vontade do tsar e visto como um marco civilizatório, Moscou despontava como bastião da Rússia ortodoxa e patriarcal, com sua miríade de igrejas e seu passado memorável (KOYRÉ 1976: 21). Em diversas passagens, o que despontava, em Maupertuis, 
PINTO, P. - O modelo heurístico orgânico na obra de F. W. J. Schelling

como uma ferramenta heurística para a compreensão dos corpos orgânicos, ou como uma base para o sistema da identidade de Schelling e para a filosofia da história de Herder, surgirá na literatura sob a forma de diversas de metáforas que visam, justamente, representar a cidade de São Petersburgo como uma criação mecânica, de finalidade extrínseca e dependente da vontade de seu criador, Pedro I - enquanto Moscou, por sua vez, surge como o fruto natural de séculos de história, como expressão, por si mesma, daquilo que constitui a Rússia como uma nação.

É isso que se vê no texto do poeta Mikhail Lérmontov, não publicado em vida, "Panorama de Moscou". Amigo próximo de Odóevski, com quem compartilhava o interesse pela obra de Schelling (apud MANÚILOV 1981: 352), Lérmontov pôde frequentar duas instituições de ensino, a Nobre Pensão e a Universidade de Moscou, que se destacaram na época por sofrer menos com a repressão oficial ao ensino da filosofia do que suas congêneres em Petersburgo ou Kazan, e que contavam em seus quadros com schellinguianos russos de renome, como M. G. Pávlov e I. I. Davýdov, cujas aulas Lérmontov provavelmente assistiu (KOYRÉ 1976 : 112, 170; MANUILOV 1981 : 125, 361). Em muitas de suas obras, Lérmontov expressaria o seu desprezo por São Petersburgo justamente por se tratar de uma cidade artificial, não russa - caráter que se estenderia inclusive à própria população da cidade (SIÉRMAN 2003: 15-41). Sollogub (apud LOTMAN 2002: 209-210) descreve até mesmo que Lérmontov, sendo um exímio pintor e desenhista, gostava de desenhar por vezes a imagem da cidade sendo inundada, como forma de castigo divino. No texto que mencionamos, o binômio Moscou-Petersburgo assume claramente as feições do binômio orgânico-mecânico, e é apresentado logo no início do texto como forma fundamental de determinação:

Moscou não é um monte frio de pedras mudas, dispostas em ordem simétrica... não! ela tem a sua alma, a sua vida. Como em um antigo cemitério romano, cada uma de suas pedras guarda uma inscrição, rabiscada pelo tempo e pelo destino; uma inscrição incompreensível para a multidão, mas rica, repleta de ideias, de sentimento e de inspiração para o homem de ciência, para o patriota e para o poeta!... (LÉRMONTOV 1964: 241 , tradução e grifo nosso)

Neste trecho, Lérmontov enfatiza também o caráter vivo da cidade, a sua capacidade de comunicação e, à semelhança das filosofias de Schelling e de Herder, o imperativo de certa comunhão entre o objeto e o espírito aguçado para que se possa penetrar no seu sentido singular, incompreensível de um ponto de vista genérico e exterior. A ausência da simetria oposta à vida e à natureza orgânica volta a aparecer na 
PINTO, P. - O modelo heurístico orgânico na obra de F. W. J. Schelling

descrição das cúpulas da Catedral de São Basílio:

[...] elas [as cúpulas] estão espalhadas por todo o edifício sem simetria, sem ordem, como ramos de uma antiga árvore, rastejando pelas suas raízes nuas (LÉRMONTOV 1964: 243, tradução nossa).

Toda a descrição do monumento da antiga moscóvia tende a fazer dele uma espécie de ser vivo: suas janelas são como "as pupilas de um monstro de cem olhos"; suas lamparinas brilham

[...] como brilha, à noite, um pirilampo por entre o musgo, envolvendo a torre quase em ruínas. Cada altar é colorido, por fora, com uma tinta especial, como se não houvessem sido construídos em um único tempo, como se cada soberano de Moscou, no decorrer de muitos anos, fosse-os juntando um a um, em homenagem ao seu anjo (LÉRMONTOV 1964: 243 , tradução nossa).

Fruto inconsciente da história, a catedral de São Basílio é oposta, no texto, à torre de Sukhariev - monumento erguido em finais do século XVII por iniciativa do demiurgo ocidentalizante, Pedro I. Nela, tudo o que se vê são as marcas de seu criador, deixando clara a dependência de sua finalidade a uma intencionalidade a ela externa - para usar os termos da filosofia de Kant:

Ela olha orgulhosa para as redondezas, como se soubesse que o nome de Pedro está impresso sobre a sua fronte musgosa! Sua fisionomia sombria, suas gigantescas proporções, tudo traz a marca de outro século, a marca daquele poder ameaçador, contra o qual nada podia se opor (LÉRMONTOV 1964: 242, tradução nossa)

A oposição entre as duas cidades, disposta nos termos orgânico-artificial, estaria presente ainda em outras obras do poeta russo, assim como na obra de outros escritores de seu tempo, como Gógol, que traria para a oposição ainda a figura de Kiev, ocupando posição idêntica à de Moscou. Lérmontov, por sua vez, voltaria a tratar do assunto em outras obras inacabadas, assumindo sempre uma postura favorável à velha capital no que ela tinha de essencialmente russo e, nesse sentido, coletivo e integrado.

\section{Conclusão}

Considerando-se a importância do debate acerca da singularidade russa diante do Ocidente ao longo de todo o século XIX, pode-se ter uma pequena dimensão da relevância que a ideia de organismo, oriunda das ciências naturais e desenvolvida pelo Romantismo alemão, viria a assumir ao se integrar a essa disputa. Nos exemplos que foram apresentados, fica claro que a simples aplicação do modelo orgânico sobre a história russa

Pandaemonium, São Paulo, v. 22, n. 37, mai.-ago. 2019, p. 377-400 
PINTO, P. - O modelo heurístico orgânico na obra de F. W. J. Schelling

já implicava, de certo modo, uma tomada de posição a favor de um desenvolvimento próprio, uma vez que, da mesma forma que não caberia exigir o voo de um avestruz, tampouco seria razoável exigir de um determinado povo um desenvolvimento idêntico ou próximo ao de outros povos, com outra história e outros costumes. Não é difícil identificar o teor político desse raciocínio, e, a despeito das pretensões universais de Schelling, ou do generoso humanismo de Herder, ele haveria fatalmente de se prestar a simplificações ideológicas grosseiras e interessadas. Todavia, não foi esta a única aplicação que semelhantes ideias receberam na Rússia, e se pode dizer, em sua defesa, que a vasta produção literária do país eslavo, dedicada a impiedosas análises do Ocidente, é, de certa forma, um pouco tributária da valoração que o modelo orgânico - conforme a formulação que recebeu de Schelling - possibilitou de sua própria realidade histórica, que pelos padrões da filosofia das Luzes haveria de surgir, fatalmente, sempre como uma nação bárbara ou, na melhor das hipóteses, simplesmente como outro país do futuro. Em última instância, é possível até mesmo afirmar que o conflito entre o princípio ocidental, mecânico, e o russo, orgânico, teriam de conviver ao longo de todo o tempo vindouro, possibilitando o processo de exclusão e derrisão mútua que nos descreve Roberto Schwarz (2005: 78-79), para quem, diante da literatura russa,

ainda os maiores romances dor realismo francês ficam parecendo ingênuos. Por que razão? Justamente, é que a despeito de sua intenção universal, a psicologia do egoísmo racional, assim como a moral formalista faziam no Império Russo efeito de uma ideologia 'estrangeira', e portanto localizada e relativa. De dentro de seu atraso histórico, o país impunha ao romance burguês um quadro mais complexo.

\section{Referências bibliográficas}

Barker, H. (ed.) Press, Politics and the Public Sphere in Europe and North America1760-1820. Cambridge: Cambridge University Press, 2004.

BERLIN, I. Russian Thinkers. Londres: Penguin, 1994.

. "O Contrailuminismo". In: BERLIN, I. Estudos sobre a humanidade. São Paulo: Companhia das Letras, 2002.

. As raizes do romantismo. Trad. Isa Mara Lando. São Paulo: Três Estrelas, 2015.

BILlington, J. H. The Icon and the Axe. Nova Iorque: Vintage Books, 1970.

Buffon, G. Oeuvres complètes, tomo II. Paris: Garnier Frères, s.d.

. Oeuvres complètes, tomo III. Paris: Duménil, 1836.

. Oeuvres complètes, tomo IV. Paris: Abel Ledoux, 1844.

BushKovitch, P. História concisa da Rússia. Trad. José Ignácio Coelho Mendes Neto. São Paulo: Edipro, 2014.

Diderot, D. Selected Philosophical Writings. Cambridge: Cambridge University Press, 1953.

ETKIND et al. (org.). Histoire de la littérature russe: Des Origines aux Lumières. Paris:

Pandaemonium, São Paulo, v. 22, n. 37, mai.-ago. 2019, p. 377-400 
PINTO, P. - O modelo heurístico orgânico na obra de F. W. J. Schelling

Fayard, 1992

FrAnK, J. Dostoiévski: as sementes da revolta, 1821-1849. Trad. Vera Pereira. 2. ed. São Paulo: Edusp, 2008.

GoMidE, B. (org). Antologia do pensamento crítico russo, 1802-1901. São Paulo: Ed. 34, 2013.

Gulyga, A. V. Herder. Moscou: Mysl', 1975.

Herder, J. G. Histoire et cultures. Trad. Max Rouché. Malesherbes: Flammarion, 2000. . Herder on Social and Political Culture. Trad. F. M. Barnard. Cambridge: Cambridge University Press, 2010.

HobsBawm, E. J. A era das revoluções. Trad. Maria T. Teixeira e Marcos Penchel. 25. ed. São Paulo: Paz e Terra, 2010.

JÚKOVA, E. P. Herder $i$ filosofsko-kul'turologítcheskaia mysl' v Rossii. Moscou: Universitiétskaia Kniga, 2007.

KoYré, A. La Philosophie et le problème national em Russie au début du XIX siècle. Paris: Gallimard, 1976.

LEBRUN, G. Kant e o fim da metafisica. 2. ed. Trad. Carlos Alberto Ribeiro de Moura. São Paulo: Martins Fontes, 2002.

LÉRMONTOV, M. I. Sobraniie sotchinenii $v$ tchetyriekh tomakh. Moscou: Khudojestvennaia Literatura, 1964.

LotMAn, I. Istóriia i tipológiia rússkoi kul'tury. São Petersburgo: Iskusstvo SPB, 2002.

Mann, I. Rússkaia Filosófskaia Estiétika. Moscou: MALL, 1998.

MANUILOV, V. A (org). Liermontovskaia Entsiklopiedia. Moscou: Sovietskaia Entsiklopedia, 1981.

MAuPertuIS, P. Oeuvres, vol II. Lyon: Jean-Marie Bruyset, 1756.

PustarnáKov, V. (org.) Friedrich Schelling: pro et contra. São Petersburgo: Izdatel'stvo Russkogo Khristianskogo Gumanitarnogo Instituta, 2001.

Ramos, M. Organic Monadology in Maupertuis. Advances in Historical Studies, v. 4, n. 1, 2015, p. 17-28.

SCHELling, F.W.J. Ideias para uma filosofia da natureza. Trad. Carlos Morujão. Lisboa: Imprensa Nacional, 2001. . Filosofia da arte. Trad. Márcio Suzuki. São Paulo: Edusp, 2010.

SCHWARZ, R. Cultura e politica. São Paulo: Paz e Terra, 2005.

SIÉRMAN, I. Mikhail Liermontov: jizn'v literaturie 1836-1841. Moscou: RGGU, 2003.

STEWART, J. (ed.). Kierkegaard and Existencialism. Farnham: Ashgate, 2011.

WALICKI, A. The Flow of Ideas. Trad. Jolanda Kozak e Hilda Andrews-Rusiecka. Frankfurt am Main: Peter Lang, 2015. 